\title{
The Risk of Thromboembolic Complications in Fontan Patients with Atrial
}

\section{Flutter/fibrillation Treated with Electrical Cardioversion}

Jiuann-Huey I Lin ${ }^{*}$, MD, PhD; Adam C Kean*, MD, MPH; Timothy M Cordes*, MD

*Department of Pediatrics, Division of Pediatric Cardiology

Indiana School of Medicine, Indianapolis, IN

${ }^{+}$Current Address: 4401 Penn Ave, Division of Pediatric Cardiac Critical Care, Children's

Hospital of Pittsburgh of UPMC, Pittsburgh, PA

Email:jiuannhuey.lin5@upmc.edu

\section{Address for correspondence:}

Corresponding Author: Timothy Cordes

Address: 705 Riley Hospital Drive, RR 227

Indianapolis IN 46202-5225

Phone: $317-274-1564$

Fax: $317-274-4022$

Email:tcordes@iu.edu

Running title: Electrical cardioversion is safe in Fontan patients with AFF

Disclosures: The authors have no disclosures.

This is the author's manuscript of the article published in final edited form as: 


\section{$\underline{\text { Abstract }}$}

Background: Atrial flutter or fibrillation (AFF) remains a major chronic complication of the Fontan procedure. This complication further predisposes this patient population to thromboembolic events. However, the incidence of thromboembolic complications in Fontan patients with AFF prior to or acutely after electrical cardioversion is unknown.

Objectives: This study aimed to characterize the risk of post-cardioversion thromboembolic events in this population.

Methods: We performed a retrospective medical record review of all patients with a history of Fontan operation treated with direct current (DC) cardioversion for AFF at Riley Children's Hospital between June 1992 and March 2014.

Results: A total of 57 patients were identified and reviewed. A total of 216 episodes of AFF required electrical cardioversion. Patients were treated with anticoagulation/antiplatelet therapy in $86.1 \%(\mathrm{n}=186)$ of AFF episodes. Right atrial or Fontan conduit clots were observed in 33 patients (57.9\%) with 61 episodes of AFF. Approximately half $(49.2 \%, \mathrm{~N}=30)$ of these episodes were treated immediately with electrical cardioversion. Twenty-five of $33(75.8 \%)$ patients with intracardiac thrombi had an atriopulmonary Fontan. Five (15.2\%) patients with a lateral caval tunnel had clots in the Fontan conduit, and three (9.1\%) patients with right atrium to right ventricular outflow tract (RVOT) connections presented with right atrial mural thrombi. Nine of the $57(15.8 \%)$ patients had documented stroke, and three (5.3\%) patients had pulmonary emboli during follow-up, although none of these emboli were associated with electrical cardioversion. Conclusion: The risk of thrombus and thromboembolism associated with AFF is high in the Fontan population. However, the risk of thromboembolism associated with cardioversion in the setting of anticoagulation is very low. 


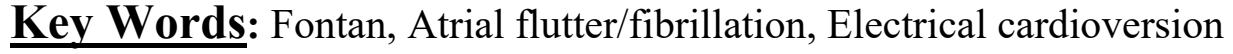




\section{Abbreviations:}

AFF: atrial flutter or fibrillation

aPTT: activated partial thromboplastin time

DC: direct current

IART: intra-atrial re-entrant tachycardia

INR: international normalized ratio transthoracic echocardiograms

RA: right atrium

RVOT: right ventricular outflow tract

TEE: trans-esophageal echocardiogram

TTE: trans-thoracic echocardiogram

tPA: tissue plasminogen activator 


\section{$\underline{\text { Introduction }}$}

Patients with single-ventricle Fontan palliation are highly susceptible to thrombus formation according to Virchow's triad of thrombogenesis, which includes abnormally low venous blood flow, hypercoagulability, and the use of intracardiac prosthetic materials with vessel wall abnormalities and endothelial injury (1). The prevalence of thrombosis after Fontan palliation is reportedly $1-33 \%$, with a high, immediate risk of thrombosis after surgery and an increased risk for Fontan patients surviving into adulthood (2-11). The anticoagulation regimens for these patients vary $(3,11)$.

Atrial flutter or fibrillation (AFF) remains a significant complication in the expanding population of Fontan palliation survivors, with an incidence of 16-17\% 5 years after Fontan surgery and an incidence of $50 \%$ by 12 years (12-14). Despite the various modifications of the Fontan surgery, including lateral caval tunnel and extracardiac conduits, as well as revisions and primary maze interventions, tachyarrhythmia persists (15). The treatment of AFF in this population is difficult. If not controlled, AFF can lead to rapid atrio-ventricular conduction, hemodynamic deterioration and sudden death (13). Given this increased morbidity and mortality, acute treatment focuses on medical and electrical cardioversion $(16,17)$. The increased risk of intra-atrial and Fontan thrombus formation in patients with AFF further complicates treatment (18).

AFF in the adult patient with an anatomically normal heart increases the risk of intraatrial thrombus and stroke (19). The risk of thromboembolic events increases with cardioversion (16). These events are caused by either mobilization of the existing thrombus or "atrial stunning" (20). These risks have defined the standard of care, which includes systemic anticoagulation for this patient population and thrombus resolution prior to cardioversion (3). Systemic 
anticoagulation prior to cardioversion has also become the standard of care for Fontan patients with AFF and documented thrombus (3).

This study sought to assess the risk of acute thromboembolism in Fontan patients with AFF who were treated with electrical cardioversion.

\section{Methods}

This study was approved by the institutional review board of the Indiana University School of Medicine.

A retrospective review of medical records was completed for all 57 eligible Fontan surgery patients with AFF who underwent electrical cardioversion between June 1992 and March 2014 at Riley Children's Hospital in Indianapolis, Indiana. During this study period, 340 Fontan procedures were performed at Riley Children's Hospital. AFF included both intra-atrial reentrant tachycardia (IART, complex atrial flutter) and atrial fibrillation. The diagnosis was confirmed by 12-lead electrocardiography, which was interpreted by the treating cardiologists as documented in the medical record. The medical record did not always distinguish the diagnostic rhythm as regular or irregular to segregate the analyses. Patients were identified using a cardiology database of electrically cardioverted patients and cross-referenced with the surgery database. Patients without Fontan palliation who underwent electrical cardioversion were excluded.

Echocardiography was performed prior to cardioversion in all patients and was interpreted by experienced echo-cardiographers. Echocardiographic evaluations were performed by an independent observer (J.L) who examined the digitized images (Syngo, Siemens) after the original examinations. These digitized images were available after January 2000. When 
transthoracic study images were sub-optimal or patients underwent electrical cardioversion with other surgical procedures, such as Fontan conversion or pacemaker generator changes, a transesophageal study was performed prior to the procedure. A thrombus was defined as an echo-reflective mass with a different texture than the underlying endocardium and evident in at least two different orthogonal planes. The thickening of the internal surface of the Fontan pathway and spontaneous contrast were not considered an intracardiac thrombus. Rarely, angiography was employed for hemodynamic evaluation, and chest computer tomography, cardiac magnetic resonance imaging or lung perfusion scan studies were completed but were never the sole means by which a thrombus was diagnosed. Organized thrombi were defined as well-circumscribed, older and non-mobile thrombi with a broad-based/secure attachment to the heart wall with occasional focal calcification (increased echo-brightness). Non-organized thrombi were defined as new thrombi with a sessile or pedunculated base that were mobile and protruding during the cardiac cycle and disappeared rapidly after anti-thrombolytic therapy.

The use of thromboprophylaxis regimens for individual Fontan patients has been at the primary cardiologist's discretion. However, our institutional approach since 2005 has been to prescribe aspirin $(5 \mathrm{mg} / \mathrm{kg} /$ day $)$ at a maximal dose of $81 \mathrm{mg}$ after the Fontan operation for primary thromboprophylaxis indefinitely in conjunction with warfarin or enoxaparin immediately after Fontan procedures with fenestration (after removal of an intra-atrial line). Enoxaparin is administered as a bridge during the initiation of warfarin. For patients on warfarin therapy, the dose was adjusted to maintain the prothrombin time and international normalized ratio (INR) between 1.8 and 2.2. The duration of this early, post-Fontan anticoagulation was at the discretion of the primary cardiologists, but most cardiologists at our institution prefer continuous anticoagulation therapy if fenestration is evident. An INR less than 1.5 was classified 
as non-compliance with warfarin administration. For patients exhibiting a mobile non-organized intra-cardiac thrombus, heparin was initially administered at a dose of 20 units $/ \mathrm{kg} /$ hour and titrated to the goal activated partial thromboplastin time (aPTT) of 53 to 84 seconds. For patients on chronic warfarin therapy, the dose for the acute treatment of intracardiac thrombi was adjusted to achieve a prothrombin time and INR between 2.5 and 3.5 for at least 2 weeks. Antithrombolytic therapy with tissue plasminogen activator (tPA) was used at the discretion of the treating cardiologists and intensivist.

Electrical cardioversion was performed 1) when there was no evidence of intracardiac thrombi; 2) when thrombi were organized; 3 ) after adequate anticoagulation therapy and the resolution of fresh thrombi by echocardiography, or 4) after a rapid ventricular response with hemodynamic compromise. Acutely successful cardioversion was defined as a sustained AFFfree rhythm until patient discharge from the recovery area. Patients with no evidence of AFF for at least 2 years after their last documented AFF were considered "AFF-free."

A thromboembolic event was defined as patients with evidence (by history, examination and imaging studies) of either central nervous system infarction (stroke) (21) or pulmonary emboli resulting in the obstruction of the pulmonary artery by thrombus. These events were confirmed by computerized tomography, magnetic resonance imaging, or autopsy.

\section{Statistical Analysis}

Descriptive statistics including the mean, median, and interquartile ranges for continuous variables and counts and percentages for categorical variables were calculated. Chi-square analysis was performed to compare mortality between patients with and without intra-cardiac thrombi. 


\section{$\underline{\text { Results }}$}

\section{Study population}

Fifty-seven patients (68.4\% male) who underwent Fontan procedures during the study period were reviewed with a median $\left(25^{\text {th }}, 75^{\text {th }}\right.$ percentile $)$ follow-up of 8.1 years $(3.25,12.9)$ from the first documented episode of AFF to last follow-up. The median age $\left(25^{\text {th }}, 75^{\text {th }}\right.$ percentile) at Fontan surgery was $5.4(3.1,6.8)$ years. The median ages of the patients who underwent the classic Fontan procedure, lateral tunnel Fontan procedure, extracardiac Fontan procedure and RA to RVOT were 7.0, 3.4, 2.9 and 6.2 years, respectively. Table 1 summarizes the patients' initial diagnoses. Table 2 summarizes the types of Fontan surgeries.

The median (25th, 75th percentile) age of the first episode of atrial flutter was 9.4 (6.9, 12.9) years after the Fontan procedure. The median (25th, 75th percentile) age of the patients who underwent electrical cardioversion was $17.3(11.1,20.8)$ years, a median $(25$ th, 75 th percentile) of $10.5(7.2,14.6)$ years after the Fontan procedure. A total of 57 patients underwent 216 electrical cardioversion procedures ( 1 procedure in 19 patients, 2 procedures in 8 patients; 3 procedures in 9 patients; 4 procedures in 5 patients, 5 procedures in 2 patients, 6 procedures in 5 patients, 7 procedures in 4 patients, 8 procedures in 1 patient, 9 procedures in 2 patients, 10 procedures in 1 patient, and 30 procedures in 1 patient). Electrical cardioversion was successful in $208(96.3 \%)$ of the 216 procedures. A significant majority of procedures were elective $(n=208$, 96.3\%). Of the eight emergent cardioversions due to a rapid ventricular response, six procedures converted to a normal sinus rhythm. Two procedures in emergent situations did not successfully convert to a normal rhythm and represented terminal events before demise.

\section{Echocardiogram}


A total of 202 transthoracic echocardiograms (TTEs) and 28 trans-esophageal echocardiograms (TEEs) were performed prior to cardioversion. Intracardiac thrombi (Figure 1) were detected in 85 TTEs and 12 TEEs in 31 patients. Intracardiac thrombi that were not observed prior to cardioversion were identified in two patients 6 years and 7 years after cardioversion on additional imaging follow-up, both of them had AFF at that time without receiving electrical cardioversion secondary to refractory to direct current cardioversion in the past. Right atrial thrombi or Fontan conduit thrombi were observed in 33 patients (57.9\%). Forty-two patients (73.7\%) presented with decreased systemic ventricular function. Eight $(14.0 \%)$ patients had at least moderate to severe systemic atrioventricular valve regurgitation, all in association with decreased systolic systemic ventricular function.

\section{Anticoagulation}

Of the 216 episodes of atrial flutter experienced by the 57 subjects, 64 (29.6\%) electrical cardioversions occurred in patients who had been taking only warfarin/heparin, 72 (33.3\%) procedures were performed on patients taking both aspirin and warfarin/heparin, $50(23.2 \%)$ procedures were performed on patients who had been taking only aspirin, and $30(13.9 \%)$ procedures were performed on patients who were not taking any anticoagulation prophylaxis, mostly due to non-compliance.

\section{Intracardiac thrombus}

Of the 33 patients with intracardiac clots, $11(33.3 \%)$ had intracardiac thrombi at the time of atrial flutter diagnosis, and $22(66.7 \%)$ had documented intracardiac clots at a later point in time after the initial episode of atrial flutter. The anatomical location and outcomes of 
intracardiac thrombi are summarized in Table 3 . Most intracardiac thrombi were observed in the systemic venous circulation, and one patient who had undergone a classic Fontan procedure exhibited a mural thrombus in the dilated right atrium and another thrombus in the left atrial appendage. One patient presenting with a dilated coronary sinus and dilated right atrium after the classic Fontan operation had recurrent coronary sinus thrombus after extracardiac Fontan conversion. He died of a massive stroke 10 months later. Three patients had a history of pulmonary emboli prior to cardioversion.

Of the sixty-one episodes of atrial flutter in patients associated with intracardiac thrombi, $38(62.3 \%)$ were organized mural thrombi, whereas $23(37.7 \%)$ were new, mobile, nonorganized thrombi. A comparison of the symptoms with intracardiac thrombi and nonintracardiac thrombi groups is summarized in Table 4. The group with intracardiac thrombi had a higher prevalence of pre-syncope and heart failure. The management of AFF with intracardiac thrombi is summarized in Figure 2. The majority of patients in the organized thrombi group received electrical cardioversion without delay in the setting of adequate anticoagulation. The patients who did not undergo electrical cardioversion were pharmacologically rate-controlled (Figure 2). Overall, only one patient with intracardiac thrombi received emergent electrical cardioversion without adequate anticoagulation; the other patient, who presented with syncope and atrial flutter with intracardiac thrombi, had received adequate anticoagulation therapy.

Resolution of intracardiac thrombi was observed in twenty-six patients (78.8\%) by either transthoracic or transesophageal echocardiogram. In nineteen patients (57.6\%), the thrombus resolved upon treatment with heparin, warfarin or their combination. In one patient with a systemic venous atrium thrombus and pulmonary emboli, the thrombi resolved upon systemic administration of tissue plasminogen activator (tPA). Local tPA injection resolved thrombi in the 
right atrium and pulmonary arteries of another patient. Five patients underwent surgical thrombectomies during Fontan conversion, and one patient received a heart transplant. One patient experienced recurrent right atrial thrombi 3 years following classic to extracardiac Fontan conversion.

\section{Long-term follow-up}

Thirty-two patients $(56.1 \%)$ continued to suffer from recurrent atrial flutter. Twenty-five patients $(43.9 \%)$ remained in normal sinus or paced rhythm. The long-term follow-up of this specific cohort revealed mortality in 14 patients (24.6\%); none of these deaths occurred during or as a result of cardioversion. The mortality rate was $27.3 \%(n=9)$ in patients with intracardiac thrombi, the mortality rate was $20.8 \%(n=5)$ in patients without intracardiac thrombi (P-value $=0.4624)$.

\section{Thromboembolic Events}

A total of 13 thromboembolic events occurred in 12 of the 57 study patients, corresponding to an overall incidence of $21.1 \%$. Nine patients experienced systemic cerebral events. One patient had a stroke prior to completion of the Fontan procedure, and 3 patients experienced cerebral embolic events prior to the first documented episode of AFF. Two patients had thrombi in either the extracardiac conduit or the coronary sinus during the cerebral thromboembolic events. None of these patients underwent fenestration in their Fontan procedure. The majority of patients who experienced thromboembolic events were taking anticoagulants at the time of the event. Three patients had pulmonary emboli with evidence of a dilated right atrium and right atrium thrombus. These three patients had all undergone the classic 
atriopulmonary Fontan operation. Two deaths occurred secondary to pulmonary emboli. Table 5 summarizes the patients with thromboembolic events. None of these events were associated with electrical cardioversion.

\section{$\underline{\text { Discussion }}$}

The following conclusions were made based on this study of patients with Fontan palliation and AFF treated with electrical cardioversion, 1. Fontan patients in our institution undergoing electrical cardioversion for AFF do not experience acute post-conversion thromboembolic events. 2. Intracardiac thrombi is much more common in Fontan patients with AFF in our study (57.8\%) compared with the reported prevalence of 1\%-33\% (2-11).

Fontan patients with AFF may be at higher risk of thromboembolism than Fontan patients without AFF due to a loss of atrial-ventricular synchrony, decreased systemic ventricular function ( $73.7 \%$ in our study), stasis in the systemic venous pathway, increased platelet activation through inflammation secondary to hypoxia (22), and, as suggested by accumulating evidence, a rapid atrial rate and rhythm associated with a pro-thrombotic state (23). Rates of systemic venous and arterial thromboembolic complications as high as $33 \%$ in Fontan patients have been reported, but the incidence of atrial flutter is unknown (2-11). Although more than half of our study patients had intracardiac thrombi, the incidence of stroke in our study patients $(15.8 \%, \mathrm{n}=9)$ was not higher than the published rates, which may be explained by the observation that the intracardiac thrombi identified in this study were mostly located in the systemic venous system.

The cohort in this study included a large number of patients who had undergone a classic Fontan procedure $(61.4 \%, \mathrm{n}=35)$. The interposition of a passive chamber between the systemic 
veins and pulmonary arteries is likely responsible for the flow inefficiency and increased energy requirements observed for a dilated right atrium (24). Because of the high incidence of dilated right atrium complications such as atrial arrhythmia and atrial thrombus formation in the atriopulmonary Fontan circulation, the Fontan procedure has been modified to include a total cavopulmonary artery connection (25) and extracardiac cavopulmonary artery connection. Surgeons at our institution stopped performing the atriopulmonary Fontan connection in 1995, and the majority of patients thereafter underwent Fontan procedures utilizing an intracardiac tunnel with or without fenestration.

Despite aggressive surgical and medical treatment, atrial flutter is difficult to treat in Fontan patients, and only $43.9 \%(\mathrm{n}=25)$ of our study patients remained free of atrial flutter. Atrial flutter is associated with a negative hemodynamic impact. Atrial flutter is poorly tolerated in Fontan patients; we observed decreased cardiac function in $73.7 \%$ of these patients. Since 1962, electrical cardioversion in the general population has enabled lower doses of maintenance antiarrhythmic medications and restoration of the rhythm to normal in more than $90 \%$ of patients (17). However, the association of stroke with cardioversion has been recognized for more than 60 years $(26,27)$. Post-cardioversion thromboembolic events can occur with a pharmacological strategy, electrical cardioversion or even spontaneous cardioversion. Although the incidence of these embolic events is less than $1 \%$ within 30 days, the risk of thromboembolic complications reaches approximately $10 \%$ in the presence of multiple risks (19). In our study, under routine surveillance of intracardiac thrombi and anticoagulation administration, none of the thromboembolic events were related to elective electrical cardioversion. Because $73.7 \%$ of AFF episodes in Fontan patients associated with decreased cardiac function and the majority of intracardiac thrombi occur in the venous/Fontan pathway, the restoration of normal sinus rhythm 
by electrical cardioversion should not be delayed. At our institution, we routinely use transthoracic echocardiograms to survey the intracardiac thrombi prior to electrical cardioversion. Consequently, cardioversion is not delayed in case of adequate anticoagulation therapy and without evidence of new, mobile and pedunculated intracardiac thrombi. A transesophageal echocardiogram was performed when the transthoracic echocardiogram images were suboptimal or when patients were sedated. For patients with intracardiac thrombi without adequate anticoagulation, heparin/warfarin was administered to achieve INR values ranging from 2.5-3.5 for at least 2 weeks. Electrical cardioversion was performed without delay if patients presented with hemodynamic compromise, irrespective of adequate anticoagulation.

As surgical techniques have improved and the number of Fontan patients has increased, our experience in the management of complications associated with Fontan palliation has also increased. Our study demonstrates that elective electrical cardioversion is not associated with an increased risk of thrombotic stroke or pulmonary emboli in this high-risk Fontan population. Thus, electrical cardioversion is safe for patients with Fontan circulation on anticoagulation therapy.

\section{$\underline{\text { Study limitations }}$}

Patients in our study did not undergo surveillance or routine central neural system imaging, and clinically silent events may have been missed. In patients with pacemaker placement, we were unable to obtain magnetic resonance images or magnetic resonance angiograms, and a small thromboembolic embolus may have been missed. Not all patients had TEEs; therefore, some small thrombi might not have been identified, particularly for patients with a poor imaging window. We recognized the possibility of missing intracardiac thrombi on a 
transthoracic echocardiogram, but none of the electrical cardioversions in our study were associated with stroke or pulmonary emboli. A retrospective study does not permit characterization of the study cohort as precisely and accurately as a well-executed prospective study. We depended on the data recorded by the physicians who performed electrical cardioversion and were responsible for the follow-up. However, because of the good coverage of electronic patient records and stability of the population, we were able to reliably review outcomes for all included patients at subsequent outpatient and hospital visits. 


\section{Perspectives:}

\section{Core Clinical Competencies and Implications}

The Fontan population is at high risk for thromboembolic complications. As AFF remains a major chronic complication of the Fontan procedure, identifying the risk of this complication is critical for proper patient management to improve outcomes. Our findings indicate that performing cardioversion is safe in Fontan patients under anticoagulation.

\section{Translational Outlook}

Further studies are needed to define the anticoagulation regimen in the growing population with contemporary modification of the Fontan operation with a less frequent IART and AFF. 


\section{Acknowledgments}

The authors would like to express our appreciation to Robert Darragh, MD, Mark Hoyer, MD, and Theresa Flaspohler, RN, for assistance with data collection and Connie Dagon for support with the IRB application. 


\section{$\underline{\text { References }}$}

1. Watson T, Shantsila E, Lip GY. Mechanisms of thrombogenesis in atrial fibrillation: Virchow's triad revisited. Lancet 2009; 373:155-166.

2. Rosenthal DN, Friedman AH, Kleinman CS, Kopf GS, Rosenfeld LE, Hellenbrand WE. Thromboembolic complications after Fontan operations. Circulation 1995; 92(9 Suppl):II287-II293.

3. McCrindle BW, Manlhiot C, Cochrane A, et al. Factors associated with thrombotic complications after the Fontan procedure: a secondary analysis of a multicenter, randomized trial of primary thromboprophylaxis for 2 years after the Fontan procedure. $\mathrm{J}$ Am Coll Cardiol 2013; 61:346-353.

4. Monagle P, Karl TR. Thromboembolic problems after the Fontan operation. Semin Thorac Cardiovasc Surg Pediatr Card Surg Annu 2002; 5:36-47.

5. Monagle P, Cochrane A, McCrindle B, Benson L, Williams W, Andrew M. Thromboembolic complications after Fontan procedures--the role of prophylactic anticoagulation. J Thorac Cardiovasc Surg 1998; 115:493-498.

6. du Plessis AJ, Chang AC, Wessel DL, et al. Cerebrovascular accidents following the Fontan operation. Pediatr Neurol 1995; 12:230-236.

7. Seipelt RG, Franke A, Vazquez-Jimenez JF, et al. Thromboembolic complications after Fontan procedures: comparison of different therapeutic approaches. Ann Thorac Surg 2002; 74:556-562.

8. Kaulitz R, Ziemer G, Rauch R, et al. Prophylaxis of thromboembolic complications after the Fontan operation (total cavopulmonary anastomosis). J Thorac Cardiovasc Surg 2005; 129:569-575. 
9. Tweddell JS, Nersesian M, Mussatto KA, et al. Fontan palliation in the modern era: factors impacting mortality and morbidity. Ann Thorac Surg 2009; 88:1291-1299.

10. Chun DS, Schamberger MS, Flaspohler T, et al. Incidence, outcome, and risk factors for stroke after the Fontan procedure. Am J Cardiol 2004; 93:117-119.

11. Ohuchi H, Yasuda K, Miyazaki A, et al. Prevalence and predictors of haemostatic complications in 412 Fontan patients: their relation to anticoagulation and haemodynamics. Eur J Cardiothorac Surg 2015; 47:511-519.

12. Collins KK. The spectrum of long-term electrophysiologic abnormalities in patients with univentricular hearts. Congenit Heart Dis 2009; 4:310-317.

13. Fishberger SB, Wernovsky G, Gentles TL, et al. Factors that influence the development of atrial flutter after the Fontan operation. J Thorac Cardiovasc Surg 1997; 113:80-86.

14. Durongpisitkul K, Porter C-J, Cetta F, et al. Predictors of early- and late-onset supraventricular tachyarrhythmias after Fontan operation. Circulation 1998; 98:1099-1107.

15. Balaji S, S, Daga A, Bradley DJ, et al. An international multicenter study comparing arrhythmia prevalence between the intracardiac lateral tunnel and the extracardiac conduit type of Fontan operations. J Thorac Cardiovasc Surg 2014; 148:576-581.

16. Mead GE, Elder AT, Flapan AD, Kelman A. Electrical cardioversion for atrial fibrillation and flutter. Cochrane Database Syst Rev 2005; 3; CD002903.

17. Lown B, Amarasingham R, Nueman J. New method for terminating cardiac arrhythmias. Use of synchronized capacitor discharge. JAMA 1962; 182:548-555.

18. Coon PD, Rychik J, Novello RT, Ro PS, Gaynor JW, Spray TL. Thrombus formation after the Fontan operation. Ann Thorac Surg 2001; 71:1990-1994. 
19. Airaksinen KEJ, Grönberg T, Nuotio I, et al. Thromboembolic complications after cardioversion of acute atrial fibrillation: the FinCV (Finnish CardioVersion) study. J Am Coll Cardiol 2013; 62:1187-1192.

20. Dagres N, Kornej J, Hindricks G. Prevention of thromboembolism after cardioversion of recent-onset atrial fibrillation: brief is not always safe. J Am Coll Cardiol 2013; 62:11931194.

21. Sacco RL, Kasner SE, Broderick JP, et al. An updated definition of stroke for the 21st century: a statement for healthcare professionals from the American Heart Association/American Stroke Association. Stroke 2013; 44:2064-2089.

22. Ninivaggi M, de Laat M, Lancé MM, Kicken CH, Pelkmans L, Bloemen S, Dirks ML, van Loon LJ, Govers-Riemslag JW, Lindhout T, Konings J, de Laat B. Hypoxia Induces a Prothrombotic State Independently of the Physical Activity. PLoS One. 2015 Oct 30;10(10)

23. Lim HS, Willoughby SR, Schultz C, et al. Effect of atrial fibrillation on atrial thrombogenesis in humans: impact of rate and rhythm. J Am Coll Cardiol 2013; 61:852860.

24. Lardo AC, del Nido PJ, Webber SA, Friehs I, Cape EG. Hemodynamic effect of progressive right atrial dilatation in atriopulmonary connections. J Thorac Cardiovasc Surg 1997; 114:2-8.

25. de Leval MR, Kilner P, Gewillig M, Bull C. Total cavopulmonary connection: a logical alternative to atriopulmonary connection for complex Fontan operations. Experimental studies and early clinical experience. J Thorac Cardiovasc Surg 1988; 96:682-695.

26. Goldman MJ. Quinidine treatment of auricular fibrillation. Am J Med Sci 1951; 222:382391. 
27. Lown B, Perlroth MG, Kaidbey S, Abe T, Harken DE. "Cardioversion" of atrial fibrillation. A report on the treatment of 65 episodes in 50 patients. N Engl J Med 1963; 269:325-331. 


\section{Figure legends}

Figure 1. Intracardiac thrombi: A) A $4.3 \times 3.12 \mathrm{~cm}$ right atrium (RA) mural thrombus (arrow) in a dilated RA imaged by TTE; B) a thrombus in the lateral caval tunnel conduit (arrow); C) a thrombus in a dilated coronary sinus (CS) (arrow); D) two thrombi (arrows) in the right atrium (RA) to pulmonary artery (PA) junction; E) TEE of a patient with an extracardiac conduit, revealing a thrombus in the posterior wall of the conduit (arrow); F) TEE of a patient who had undergone a classic Fontan revealing a swirling flow in the dilated right atrium (RA).

Figure 2. Flow chart of treatment for patients presenting with AFF associated with intracardiac thrombi. DC: direct current. 
Table 1. Patient's demography; N (\%)

\begin{tabular}{|l|r|}
\hline Male & $39(68.4 \%)$ \\
\hline LV dominant & $40(70.2 \%)$ \\
\hline Tricuspid atresia & $20(35.1 \%)$ \\
\hline Double inlet of left ventricle & $10(17.5 \%)$ \\
\hline Pulmonary atresia & $7(12.3 \%)$ \\
\hline Criss-Cross with hypoplastic RV & $2(03.5 \%)$ \\
\hline Unbalanced AV canal/hypoplastic RV & $1(01.8 \%)$ \\
\hline RV Dominant & $17(29.8 \%)$ \\
\hline Hypoplastic left heart syndrome & $9(15.7 \%)$ \\
\hline DORV with mitral stenosis/mitral atresia & $4(07.0 \%)$ \\
\hline Unbalanced AV canal/hypoplastic LV & $2(03.5 \%)$ \\
\hline Criss-Cross with hypoplastic LV & $1(01.8 \%)$ \\
\hline Corrected TGA with hypoplastic LV, severe PS & $1(01.8 \%)$ \\
\hline
\end{tabular}

AV: atrioventricular, DORV: double outlet of right ventricle, LV: left ventricle, PS: pulmonary stenosis, RV: right ventricle, TGA: transposition of great arteries 
Table 2. Type of Fontan operation; N (\%)

\begin{tabular}{|c|l|l|}
\hline Type of Fontan operation & Surgical interventions noted in follow-up & \\
\hline Atriopulmonary connection & Convert to extracardiac conduit with MAZE & $16 / 35(45.7 \%)$ \\
\cline { 2 - 3 } $35 / 57(61.4 \%)$ & Convert to extracardiac conduit & $01 / 35(02.9 \%)$ \\
\cline { 2 - 3 } & Convert to lateral caval Fontan & $02 / 35(05.7 \%)$ \\
\cline { 2 - 3 } & Heart transplant & $02 / 35(05.7 \%)$ \\
\hline $\begin{array}{c}\text { Lateral caval tunnel } \\
17 / 57(29.8 \%)\end{array}$ & Convert to extracardiac conduit with MAZE & $01 / 17(05.9 \%)$ \\
\hline $\begin{array}{c}\text { Right atrium to RVOT } \\
\text { connection } \\
03 / 57(05.3 \%)\end{array}$ & Convert to two ventricle repair with MAZE & $01 / 03(33.3 \%)$ \\
\cline { 2 - 3 } & Convert to extracardiac conduit with MAZE & $02 / 03(66.7 \%)$ \\
\hline $\begin{array}{c}\text { Extracardiac conduit } \\
02 / 57(03.5 \%)\end{array}$ & No conversions & \\
\hline
\end{tabular}

RVOT: right ventricular outflow tract 
Table 3 Location and clinical outcome of inatracardiac thrombus

\begin{tabular}{|l|c|c|c|}
\hline Fontan connection & Classic & Lateral caval tunnel & RA to RVOT \\
\hline Intracardiac thrombus & $25 / 35(71.4 \%)$ & $5 / 17(29.4 \%)$ & $3 / 3(100 \%)$ \\
\hline $\begin{array}{l}\text { Location of the intracardiac } \\
\text { thrombi }\end{array}$ & & & \\
\hline RA & 17 & 0 & 3 \\
\hline RA/IVC & 3 & 0 & 0 \\
\hline RA/SVC & 2 & 0 & 0 \\
\hline RA/PA & 1 & 0 & 0 \\
\hline RA and LAA & 1 & 0 & 0 \\
\hline CS & 1 & 3 & 0 \\
\hline Fontan conduit & 0 & 1 & $2 / 3(66.7 \%)$ \\
\hline Conduit/IVC & 0 & $4 / 5(80 \%)$ & 2 \\
\hline $\begin{array}{l}\text { Resolution of intracardiac } \\
\text { thrombi }\end{array}$ & $20 / 25(80.0 \%)$ & 3 & 0 \\
\hline $\begin{array}{l}\text { Coumadin } \\
\text { Heparin + Coumadin }\end{array}$ & 7 & 1 & 0 \\
\hline tPA & 6 & 0 & 0 \\
\hline $\begin{array}{l}\text { Surgical thrombectomy } \\
\text { heart transplantation }\end{array}$ & 1 & 0 & 1 \\
\hline $\begin{array}{l}\text { Recurrence of RA thrombus } \\
\text { after Fontan Conversion }\end{array}$ & 1 & 0 & \\
\hline
\end{tabular}

CS: coronary sinus, LAA: left atrial appendage; IVC: inferior vena cava; PA: pulmonary artery, RA: right atrium, SVC: superior vena cava, tPA: tissue plasminogen activator 
Table 4. Symptoms associated with atrial flutter/fibrillation

\begin{tabular}{|l|c|c|c|}
\hline Symptoms & $\begin{array}{l}\text { Group of Intracardiac } \\
\text { thrombi } \\
(\mathrm{N}=61) \mathrm{N}(\%)\end{array}$ & $\begin{array}{l}\text { Group of no } \\
\text { intracardiac thrombi } \\
(\mathrm{N}=155) \mathrm{N}(\%)\end{array}$ & $\mathrm{P}$ value \\
\hline Asymptomatic & $08(13.11 \%)$ & $20(12.9 \%)$ & $\mathrm{P}=0.089$ \\
\hline Palpitation & $39(63.93 \%)$ & $117(75.48 \%)$ & $\mathrm{P}=0.134$ \\
\hline Chest pain & $18(29.51 \%)$ & $31(20.00 \%)$ & $\mathrm{P}=0.331$ \\
\hline Syncope/Collapse & $02(03.28 \%)$ & $02(01.29 \%)$ & $\mathrm{P}=0.004 *$ \\
\hline Dizziness/pre-syncope & $12(19.67 \%)$ & $10(06.45 \%)$ & $\mathrm{P}=0.087$ \\
\hline Edema/Ascites & $10(16.39 \%)$ & $12(07.74 \%)$ & $\mathrm{P}=0.134$ \\
\hline Fatigue & $18(29.51 \%)$ & $31(20.00 \%)$ & $\mathrm{P}=0.416$ \\
\hline Dyspnea & $20(32.79 \%)$ & $33(21.29 \%)$ & $\mathrm{P}=0.656$ \\
\hline GI symptoms & $14(22.95 \%)$ & $28(18.06 \%)$ & $\mathrm{P}<0.001^{*}$ \\
\hline Hypoxia & $08(13.11 \%)$ & $17(11.0 \%)$ & $91(58.71 \%)$ \\
\hline Heart failure & $53(86.89 \%)$ & & \\
\hline
\end{tabular}


Table 5. Data of Patients with symptomatic thromboembolic events

\begin{tabular}{|c|c|c|c|c|c|c|c|c|c|c|c|c|}
\hline & \multicolumn{9}{|c|}{ Systemic thromboembolic event } & \multicolumn{3}{|c|}{ Venous } \\
\hline & Patient 1 & Patient 2 & Patient 3 & Patient 4 & Patient 5 & Patient 6 & Patient 7 & Patient 8 & Patient 9 & Patient 10 & Patient 11 & Patient 12 \\
\hline Anatomy & $\begin{array}{c}\text { Unbalance } \\
\text { d AV canal } \\
\text { with } \\
\text { HLHS } \\
\end{array}$ & TA & $\begin{array}{c}\text { TA with } \\
\text { TGA }\end{array}$ & TA & $\begin{array}{c}\text { Unbalance } \\
\mathrm{d} \text { AV canal } \\
\text { defect with } \\
\text { HRV } \\
\end{array}$ & DILV & DILV & HLHS & HLHS & $\mathrm{TA}$ & $\mathrm{TA}$ & DILV \\
\hline Type of surgery & $\begin{array}{l}\text { Classic } \\
\text { /TCPC }\end{array}$ & $\begin{array}{c}\text { RA to } \\
\text { RVOT / } \\
\text { TCPC }\end{array}$ & Classic & Classic & Classic & Classic & $\begin{array}{c}\text { Lateral } \\
\text { caval } \\
\text { tunnel }\end{array}$ & $\begin{array}{c}\text { Lateral } \\
\text { caval } \\
\text { tunnel }\end{array}$ & $\begin{array}{c}\text { Lateral } \\
\text { caval } \\
\text { tunnel }\end{array}$ & Classic & Classic & Classic \\
\hline $\begin{array}{l}\text { Thromboembolic } \\
\text { event }\end{array}$ & stroke & $\begin{array}{c}\text { Massive } \\
\text { stroke }\end{array}$ & stroke & stroke & stroke & stroke & stroke & $\begin{array}{c}\text { Multiple } \\
\text { micro- } \\
\text { embolic } \\
\text { stroke }\end{array}$ & stroke & $\begin{array}{c}\text { Pulmonary } \\
\text { embolism }\end{array}$ & $\begin{array}{l}\text { Pulmonary } \\
\text { embolism }\end{array}$ & $\begin{array}{c}\text { Pulmonary } \\
\text { embolism }\end{array}$ \\
\hline $\begin{array}{l}\text { Relationship } \\
\text { between the event } \\
\text { and electrical } \\
\text { cardioversion }\end{array}$ & $\begin{array}{c}34 \text { days } \\
\text { after a } \\
\text { spontaneou } \\
\text { s convert } \\
\text { atrial } \\
\text { flutter }\end{array}$ & $\begin{array}{c}13.5 \\
\text { years } \\
\text { after last } \\
\text { cardio- } \\
\text { version }\end{array}$ & $\begin{array}{l}13 \text { years } \\
\text { prior to } \\
\text { first } \\
\text { episode of } \\
\text { atrial } \\
\text { flutter }\end{array}$ & $\begin{array}{c}\text { After } \\
\text { ablation }\end{array}$ & $\begin{array}{l}10.7 \text { ears } \\
\text { prior to his } \\
\text { first } \\
\text { episode of } \\
\text { atrial } \\
\text { flutter }\end{array}$ & $\begin{array}{c}\text { After } \\
\text { diagnostic } \\
\text { cath }\end{array}$ & $\begin{array}{c}\text { After } \\
\text { Fontan } \\
\text { operation, } \\
7 \text { years } \\
\text { prior to } \\
\text { first } \\
\text { episode of } \\
\text { atrial } \\
\text { flutter }\end{array}$ & $\begin{array}{c}12 \text { months } \\
\text { after } \\
\text { cardio- } \\
\text { version }\end{array}$ & $\begin{array}{l}2 \text { days } \\
\text { prior to } \\
\text { cardio- } \\
\text { version }\end{array}$ & $\begin{array}{l}5 \text { days } \\
\text { prior to } \\
\text { cardio- } \\
\text { version }\end{array}$ & $\begin{array}{c}1 \text { day prior } \\
\text { to } \\
\text { emergent } \\
\text { cardio- } \\
\text { version }\end{array}$ & $\begin{array}{c}14 \text { years } \\
\text { after last } \\
\text { cardio- } \\
\text { version }\end{array}$ \\
\hline $\begin{array}{l}\text { Intracardiac } \\
\text { thrombi }\end{array}$ & $\begin{array}{l}\text { Extra- } \\
\text { cardiac } \\
\text { conduit }\end{array}$ & $\begin{array}{l}\text { Coronar } \\
\text { y sinus }\end{array}$ & No & No & No & No & No & No & No & $\begin{array}{c}\text { Right } \\
\text { atrium }\end{array}$ & $\begin{array}{c}\text { Right } \\
\text { atrium }\end{array}$ & $\begin{array}{l}\text { Right } \\
\text { atrium }\end{array}$ \\
\hline Age at event & $16.4 \mathrm{y} / \mathrm{o}$ & $39.3 \mathrm{y} / \mathrm{o}$ & $6 y / 0$ & $13.6 \mathrm{y} / \mathrm{o}$ & $6.3 \mathrm{y} / \mathrm{o}$ & $18 \mathrm{~m} / \mathrm{o}$ & $12 \mathrm{y} / \mathrm{o}$ & $10.1 \mathrm{y} / \mathrm{o}$ & $9.7 \mathrm{y} / \mathrm{o}$ & $20.1 \mathrm{y} / \mathrm{o}$ & $34.6 \mathrm{y} / \mathrm{o}$ & $30 \mathrm{y} / \mathrm{o}$ \\
\hline Anticoagulant & $\begin{array}{c}\text { warfarin } \\
\text { aspirin }\end{array}$ & $\begin{array}{c}\text { No } \\
\text { (non- } \\
\text { complia } \\
\text { nt) }\end{array}$ & aspirin & $\begin{array}{c}\text { warfarin } \\
\text { aspirin }\end{array}$ & aspirin & warfarin & No & aspirin & aspirin & tPA & Heparin & tPA \\
\hline Outcome & $\begin{array}{l}\text { mild fine } \\
\text { motor } \\
\text { deficient, } \\
\text { almost } \\
\text { complete } \\
\text { resolution } \\
\text { of left } \\
\text { hemi- } \\
\text { paresis } \\
\end{array}$ & $\begin{array}{c}\text { Died } \\
\text { from } \\
\text { massive } \\
\text { embolic } \\
\text { stroke }\end{array}$ & $\begin{array}{c}\text { Residual } \\
\text { left } \\
\text { hemiparesi } \\
\text { s }\end{array}$ & $\begin{array}{c}\text { Died of } \\
\text { massive } \\
\text { cerebellar } \\
\text { embolic } \\
\text { stroke } 11 \\
\text { months } \\
\text { later }\end{array}$ & $\begin{array}{c}\text { Residual } \\
\text { left } \\
\text { hemiparesi } \\
\mathrm{s}\end{array}$ & $\begin{array}{c}\text { Resolution } \\
\text { of left } \\
\text { hemiparesi } \\
\text { s }\end{array}$ & $\begin{array}{c}\text { Resolution } \\
\text { of left } \\
\text { hemi- } \\
\text { paresis }\end{array}$ & $\begin{array}{c}\text { Improved } \\
\text { memory, } \\
\text { attends } \\
\text { regular } \\
\text { classes }\end{array}$ & $\begin{array}{c}\text { Resolution } \\
\text { of } \\
\text { hemiparesi } \\
\text { s but died } \\
\text { of plastic } \\
\text { bronchitis } \\
\text { and heart } \\
\text { failure } 6 \\
\text { years later }\end{array}$ & $\begin{array}{c}\text { Resolution } \\
\text { of } \\
\text { thrombus }\end{array}$ & $\begin{array}{c}\text { Died of } \\
\text { heart } \\
\text { failure and } \\
\text { pulmonary } \\
\text { emboli }\end{array}$ & $\begin{array}{c}\text { Resolution } \\
\text { of } \\
\text { pulmonary } \\
\text { emboli but } \\
\text { died of } \\
\text { MOF }\end{array}$ \\
\hline
\end{tabular}

